\title{
A Comparative Study of the Recommendation Algorithm Applicate in the Network of Educational Resources Platform
}

\author{
Han Jun ${ }^{\text {a }}$, Yang Fan ${ }^{\mathrm{b}}$, Liu Jing ${ }^{\mathrm{c}}$, Tong Jun ${ }^{\mathrm{d}}$, Chen Shuo ${ }^{\mathrm{e}}$ \\ Department of Educational Technology, Capital Normal University, Beijing, 100048, China

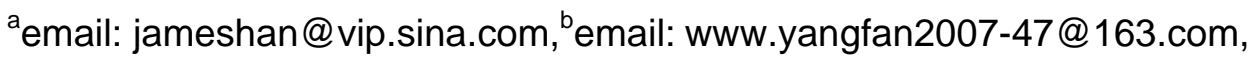 \\ cemail: fionaliujing @163.com, ${ }^{\mathrm{d}}$ email: tongjun02.student@sina.com, \\ eemail:cskanyandota@sina.com
}

\begin{abstract}
Keywords: Educational Resources; The Network Education Resources; Educational Resources Platform; Recommendation Algorithm
\end{abstract}

\begin{abstract}
Recommended information that meet their interests and needs for users. With the increasing number of educational resources, recommendation system has been introduced in construction of educational resources platform. This paper is to analyze the status of educational resources and educational resource platform. According to the characteristics of the different recommendation algorithms compared advantages and disadvantages of recommendation algorithms in the application of educational resources platform, and analyze the causes of problems and consequences.
\end{abstract}

\section{Introduction}

Based on the "Long-term Education Reform and Development Plan (2010-2020) "proposing the concept of education information. All provinces promote the construction of digital learning resources actively. The Ministry of Education and related agencies have been built 300multi-disciplinary new Century Network program, more than 1,000 doors national quality courses, more than 20,000 doors online education courses, 18 University Museums, 12 key disciplines information resources mirror systems, The Higher Education Literature Guarantee Systems, National Basic Education Resources Networks and applicable educational resources platforms for students from different grades at different levels.[2] Facing the complex network educational resources, how to conduct effective information discovery and knowledge mining so that the network educational resources to take full advantage of learners has become the current problems to be solved.

\section{Educational resources and network education resources}

In broad scope, educational resource is a concept in economics that science used in the field of education. For a country, educational resource is allocation of the total resources of the state in education. Educational resource is allocated between the regional education, education at all levels and at all levels of school. [3]

In narrow terms, "educational resources construction technical specification CELTS-31 "(2002 formulation) will be educational resources described as" contains specific educational information, all kinds of information resources have certain value of education, especially the education information transmitted on the Internet with digital signal. Digitization and the value of education are two core features of educational resources. Its development has a very high technical requirements and educational requirements. "[4]

The development of network education requires generation a large number of educational resources must be adapted. These educational resources must be able to save and circulate in the network. Therefore, people call the combination of network education resources and education application of network education resources. [5] This definition of network education resources 
category is very broad. Thus, Professor Zhu Zhiting divided with its manifestations into a network of environmental resources, the network of human resources and network education information resources.

\section{Education resources platform construction situation at home and abroad}

A The Domestic Educational Resources Platform Construction Status Maintaining the Integrity of the Specifications

Along with the continuous deepening of education informatization process, educational resources platform received extensive attention, resulting in friendliness and normative gradually strengthened. However, there are some questions in the process of building educational resources platform:

1) A lot of manpower, material resources and financial resources devoted to education resources development, leading to education resources total quantity is large, but the high quality education resources are relatively scarce.

2) Education resources construction mechanism and standards are not perfect.

3) Education resource type and classification form single, use is not reasonable.

\section{B Foreign EducationalResources Platform Construction Status}

As America's most famous education resources platform "TheGateWay" for analysis. The platform does not place any educational resource ontology, rely mainly on an records database described by the metadata of educational resource and a search engine technology to manage and take advantage of all the educational resources in the Union. From improving ease of use of the search tool and reduce the teachers use the difficulty, the platform choose the most concentrated reflect the characteristics of the education resources three elements constitute a search interface: grade, subject and keyword. It uses a combination of search, including two combination of keywords, a theme, the two topics, the grade specified, and whether only need to free resources five search criteria items. You can ask the search results at the same time to satisfy one or more conditions to increasing the search accuracy. [6]

At present, foreign education resources platform development model and scale are relatively mature, mainly reflected in the following aspects:

1) Classification of network education resources at all levels clear, conforms to the characteristic of education resources users at all levels Foreign educational resources, according to difference of learners are affected by education, are divided by grades: pre-school, the kindergarten ,grades 1-12, higher education, adult education, community education. Education resources at all levels hierarchical systematic and specific, is convenient for all user reference and learning .

2) Network education resources are easy to share and use, resource-rich and full of humanity. In addition to develop a large number of quality educational resources in platform, also provides links to external resources, so that users with quick and easy retrieval external educational resources, expanding the scope of the use of resources effectively. [7]

3) Network education resources development systematically, making fine. Foreign educational resources platform not only focus on the construction of the platform structure, also focus on the design and development of educational resources ontology. They often set up dedicated resource development team ,based instructional design, and take school and company cooperation pattern design and development education resources of friendliness interface and interactive.

4) Network education resources are scheduled maintenance and updated quickly. Educational resources are updated timely to ensure that attract the masses of users. Resource construction is not a one-time work, high quality education resources platform construction is a long-term accumulation of results.

Network education resources presented in the form of theme, subject resources auxiliary thematic resources. Foreign network educational resources using the problem tissue materials, combined the knowledge of many disciplines, in order to implement interdisciplinary teaching. Around a comprehensive subject, offers more abundant resources than the curriculum content to help students development perspective and deepening the understanding. At the same time, the resource contains multiple perspectives of a problem, to help to cultivate students' critical thinking and creative thinking. 


\section{A comparison of recommendation algorithm apply in education resources platform}

A Introduction of Several Kinds of Recommendation Algorithm

1) Collaborative filtering recommendation algorithm

Collaborative filtering algorithm is one of the most widely used recommendation techniques. It is based on a similar association between the user or item to predict the individual user preferences. The basic idea of collaborative filtering is the first collaboration, and filtered. Due to the collaborative filtering technology focus on the users of the item evaluation does not pay attention to the content of the item itself, so it can handle like music, movies and other complex items set. Collaborative filtering recommendation can be divided into two types: user-based collaborative filtering algorithm and item-based collaborative filtering algorithm.

User-based collaborative filtering algorithm (User-based CF) is the first generation of collaborative filtering technology. It is based on the fact that each user has its interests similar users, this group users called the current user's "neighbors", these neighbor users interested in items can be used as the basis of the user program recommends. User-based CF algorithm can be divided into two steps:

a) To find user group that most similar to the target user - "the nearest neighbors". The similarity can be judged by the behavior selection vector of users. Currently, there are many algorithms that compare the behavior selection vector similarity. The classic algorithms are Person Correlation Coefficient and Cosine-based Similarity.

b) Calculated set of users are most interested in the item (also called TopN recommendation sets). Calculated respectively statistics the favorite of the "nearest neighbor" in the different items, and then take one of the favorite high degree of item as a recommended set. Getting users are most interested in item set (also called TopN recommendation sets).

Item-based collaborative filtering compare the similarity between item and item, compared with the user-based collaborative filtering saves the amount of calculation to find the nearest neighbors , the calculation efficiency is greatly increased. The basic idea is: a user will like items which are similar with their favorite items. Item-based CF equally divided into two steps:

a) Getting the item history score record, namely user behavior choice vector on each item;

b) After comparing the behavior choice vector on each item and calculating similarity between items, then get similar item recommendation.

2) Content-based recommendation algorithm

Content-based recommendation (the content - -based/CB) is a continuation of the collaborative filtering technology. Each of those items is described with the characteristics of its attributes. Items classification is based on the similarity of the characteristic attributes, and then obtain a similar project that the user's favorite items as recommended. The content-based recommendation also requires users' historical data. The advantage of this recommendation does not depend on other users' data, thus avoiding the problem of "cold start" and "sparse", and recommending for users with special flavors. The disadvantage is that requirements of structural of recommended items, and the preferences of the user's interest must be able to be expressed in the form of project characteristics. In addition, content-based recommendation can only recommend the similar items which are users interested in. New items of users interested cannot be found. [8]

B Introduction of Several Kinds of Recommendation Algorithm 
Table1 The Comparison

\begin{tabular}{|c|c|c|c|}
\hline $\begin{array}{l}\text { Recommendation. } \\
\text { algorithm. }\end{array}$ & $\begin{array}{l}\text { Recommended } \\
\text { conditions.s }\end{array}$ & Input., & Main ideas., \\
\hline $\begin{array}{l}\text { Collaborative } \\
\text { filtering }\end{array}$ & $\begin{array}{l}\text { Leamers' } \\
\text { evaluations of } \\
\text { educational } \\
\text { resources.r }\end{array}$ & $\begin{array}{l}\text { Leamers' } \\
\text { evaluation } \\
\text { rank of } \\
\text { educational } \\
\text { resources.r }\end{array}$ & $\begin{array}{l}\text { Identify learner's } \\
\text { neighbors, and then } \\
\text { generate the score } \\
\text { of educational } \\
\text { resources to predict } \\
\text { of current } \\
\text { prediction. }\end{array}$ \\
\hline Content-based. & $\begin{array}{l}\text { Characteristic } \\
\text { attributes of the } \\
\text { educational } \\
\text { resources. }\end{array}$ & $\begin{array}{l}\text { Leamers' } \\
\text { evaluation } \\
\text { rank of } \\
\text { educational } \\
\text { resources.r }\end{array}$ & $\begin{array}{l}\text { According to the } \\
\text { learner's score } \\
\text { generated classifier } \\
\text { of education } \\
\text { resources. }\end{array}$ \\
\hline Knowledge-based.r & $\begin{array}{l}\text { Characteristics of } \\
\text { the educational } \\
\text { resources and } \\
\text { how educational } \\
\text { resources to meet } \\
\text { the learners' } \\
\text { knowledge. }\end{array}$ & $\begin{array}{l}\text { A } \\
\text { description } \\
\text { of leamers' } \\
\text { needs and } \\
\text { interests.. }\end{array}$ & $\begin{array}{l}\text { Calculate the match } \\
\text { degree between the } \\
\text { current forecast } \\
\text { educational } \\
\text { resources and the } \\
\text { needs of leamers. }\end{array}$ \\
\hline Association -based.? & $\begin{array}{l}\text { The learners' } \\
\text { browse or } \\
\text { purchase history. }\end{array}$ & $\begin{array}{l}\text { Browse and } \\
\text { buy records. }\end{array}$ & $\begin{array}{l}\text { Generate } \\
\text { association rules, } \\
\text { and then generated } \\
\text { recommendations }\end{array}$ \\
\hline
\end{tabular}

Table2 Comparison of the advantages and disadvantages of recommendation algorithm[10]

\begin{tabular}{|c|c|c|}
\hline $\begin{array}{l}\text { Recommendation } \\
\text { algorithm. }\end{array}$ & Advantage.r. & Disadvantage. \\
\hline $\begin{array}{l}\text { Collaborative } \\
\text { filtering.r }\end{array}$ & $\begin{array}{l}\text { Help to find a new interest } \\
\text { and extend new vision; } \\
\text { Don't need domain } \\
\text { knowledge; Over time, } \\
\text { the performance is } \\
\text { improved; Recommend } \\
\text { personalized, high degree } \\
\text { of automation; Deal the } \\
\text { complex unstructured } \\
\text { object. }\end{array}$ & $\begin{array}{l}\text { "Cold start", Sparseness, } \\
\text { New users, Scalability } \\
\text { issues;The quality } \\
\text { depends on the historical } \\
\text { data set, System at the } \\
\text { beginning of the } \\
\text { recommendation quality is } \\
\text { poor; The system } \\
\text { recommended quality is } \\
\text { not improved with the } \\
\text { growing interest set. }\end{array}$ \\
\hline Content-based. & $\begin{array}{l}\text { Recommendation result is } \\
\text { intuitive, easy to explain; } \\
\text { Don't need domain } \\
\text { knowledge. }\end{array}$ & $\begin{array}{l}\text { New user issues; Hard to } \\
\text { deal the complex } \\
\text { attributes; Need for } \\
\text { adequate data structure } \\
\text { classifier.r }\end{array}$ \\
\hline Knowledge-based. & $\begin{array}{l}\text { Maps the user } \\
\text { requirements on product; } \\
\text { Consider the non-product } \\
\text { attributes. }\end{array}$ & $\begin{array}{l}\text { Knowledge acquisition is } \\
\text { difficult; Recommended is } \\
\text { static. }\end{array}$ \\
\hline Association -based. & $\begin{array}{l}\text { Be able to find new points } \\
\text { of interest; Don't need } \\
\text { domain knowledge; }\end{array}$ & $\begin{array}{l}\text { Association rules abstract } \\
\text { difficult and } \\
\text { time-consuming; Low } \\
\text { degree of personalization. }\end{array}$ \\
\hline
\end{tabular}

1) Knowledge-based recommendation algorithm

Knowledge -based recommendation is not based on user needs and preferences. It is a kind of inference technique. The concept of functional knowledge is presented, we can understand the knowledge to achieve some function. This feature is how to make a project to meet the needs of a particular user, so it is able to explain the relationship between demanding and recommending. Users information can be any reasoning knowledge structure can support.

2) Association -based recommendation algorithm

Association-based recommendation is depending on the rules of the prior generation to recommend items to users. The rules reflect the relationship between the two types of items set .It is an If-Then statement. Currently, most of the association-based recommendation systems are used in e-commerce sites. The advantage is simply and directly, the disadvantage is to explore meaningful associations more difficult and time-consuming, difficult to ensure the quality of the associations. In addition, with the increase in the number of associations, the management of the system will be more difficult. [9]

\section{Comparison of the Advantages and Disadvantages of Recommendation Algorithm in Educational Resources Platform Application}

Collaborative filtering algorithm needs to scan the entire database to calculate the learners' similarity. Therefore, with the learners' record in the database increasing, its computational complexity is increasing with exponential multiples, leading to the recommendation system performance degradation. For educational resources platforms of large numbers of users, if different learners did not score on the same resources, even if the interests of the two learners are the same, the system cannot come to their similarity, which cannot do precise recommend. When new resources are added to the educational resources platform, due to new resource just added, no one or few evaluation, then the resources are difficult to recommend out. New user issues refer the user's classification in recommendation system is based on the target user and other users comparison, this comparison is mainly based on the continuously accumulated user evaluation. If a new user never evaluate in the system, the system cannot inform its interests and not recommend. Therefore, collaborative filtering recommendation algorithm and content-based recommendation algorithm 
have some limitations.

Knowledge-based recommendation algorithm results do not change according to the needs of learners, which largely affect the recommended precision.

The rule-based recommendation algorithm is a key step abstract association rules, and the association rules extraction is carried out on the basis of the analysis in the data. The recommendation results' personalization is low and not easy to have surprises on users.

To sum up, only used one or two recommendation algorithms cannot satisfy the user requirements, and cannot get the expected result. Such as Table 2:

\section{Conclusion}

The simple way to judge the pros and cons of an algorithm is to look at the difference between prediction result and score results of learners. Through the comparison of the above several kinds of recommendation algorithm, it is not difficult to find citing a single one recommendation algorithm in the educational resources platform will have some problems. So, if want to provide quality and efficient recommendation for learners, must be apply several kinds of recommendation algorithm, combined with its own attributes and characteristics of the educational resources platform. Only a variety of recommendation algorithms learn from each other to avoid their own problems to recommend a learner satisfaction of learning resources.

\section{Acknowledgement}

In this paper, the research was sponsored by Department of Educational Technology of Capital Normal University.

\section{References}

[1] Xiang Liang, Recommended Practice [M]. People's Posts and Telecommunications Press.

[2] Zeng Haijun and so on. Online Education Resources Construction and Sharing Based on the Excellent Course Evaluation Index [J].Distance Education in China, 2007, vol.10. pp:47-52.

[3] Shang Yakun, Beijing Higher Education Resource Sharing Problem Research [D]. Beijing: China Geological University, 2008.

[4] Educational Resources Construction Technical Specifications CELTS-31 (2002).

[5] Wu Zhonglin, Higher Network Educational Resources Construction Research [D].Liaoning: Dalian University of Technology, 2005.

[6] Li Jiahou and so on. American Education Resource Portal and Its Enlightenment on China Education Resources Construction [J]. E-education Research,2003,vol.08.pp:66-71.

[7] Huang Qin, Web Data Mining Research and Its Application in the Network Learning Personalized Recommendation [D].Hunan: Hunan University, 2004.

[8] Yu Li, E-commerce Personalization: Theory, Methods and Applications [M]. Tsinghua university press, 2007.

[9] Yu Xiaogao, E-commerce Intelligent Recommendation System Research [M]. Hubei people press,2012.

[10] Joseph A. Konstan, John Riedl, How Amazon and Netflix predict your preferences and prod you to purchase $[\mathrm{J}] .2012-10$. 